\title{
A Review on the Oral Health Impacts of Acculturation
}

\author{
Xiaol-Li Gao $\cdot$ Colman McGrath
}

Published online: 17 November 2010

(C) The Author(s) 2010. This article is published with open access at Springerlink.com

\begin{abstract}
The impact of acculturation on systemic health has been extensively investigated and is regarded as an important explanatory factor for health disparity. However, information is limited and fragmented on the oral health implications of acculturation. This study aimed to review the current evidence on the oral health impact of acculturation. Papers were retrieved from five electronic databases. Twenty-seven studies were included in this review. Their scientific quality was rated and key findings were summarized. Seventeen studies investigated the impacts of acculturation on the utilization of dental services; among them, 16 reported positive associations between at least one acculturation indicator and use of dental services. All 15 studies relating acculturation to oral diseases (dental caries and periodontal disease) suggested better oral health among acculturated individuals. Evidence is lacking to support that better oral health of acculturated immigrants is attributable to their improved dental attendance. Further researches involving other oral health behaviors and diseases and incorporating refined acculturation scales are needed. Prospective studies will facilitate the understanding on the trajectory of immigrants' oral health along the acculturation continuum.
\end{abstract}

Keywords Acculturation - Immigrants - Ethnicity · Oral health · Dental care

X.-L. Gao $(\bowtie)$. C. McGrath

Dental Public Health, Faculty of Dentistry, The University of

Hong Kong, Prince Philip Dental Hospital, 34 Hospital Road,

Sai Ying Pun, Hong Kong

e-mail: gaoxl@hkucc.hku.hk

\section{Introduction}

The last century has witnessed marked acceleration of international immigration, mostly from less developed countries to more developed countries. From year 1970 to 2002 , the number of people living outside their countries of birth grew from 80 to 185 million worldwide, leading to an increasing ethnic and racial diversification of populations in many countries [1]. Upon arriving in a new society, immigrants are exposed to a new culture and are subject to a process of acculturation. Acculturation, as a term in anthropology, comprehends those phenomena when groups of individuals having different cultures come into continuous first hand contact, with subsequent changes in the original culture patterns of either or both groups [2]. Pertaining to ethnic minorities, there are four distinct possible outcomes of their acculturation, namely assimilation (movement toward the dominant culture), rejection (reaffirmation of the traditional culture), integration (synthesis of the two cultures), or marginalization (alienation from both cultures) [3]. The speed and extent of acculturation vary among individuals and have practical implications on one's health.

The impacts of acculturation on health began gaining prominence since 1960s, pioneered by the research work linking acculturation and cardiovascular diseases [4]. The interest in acculturation as an explanatory variable for health has proliferated and steadily increased over the past 40 years with almost 2,000 articles published [5]. Acculturation, examined with regard to a wide variety of health behaviors, appeared to be beneficial to some health behaviors, and detrimental to others [6]. Evidence collected in the United States has shown that acculturation exerts a positive effect on use of health services [7,8], negative effects on alcohol use $[9,10]$ and diet $[11,12]$, and both positive effect [11] and negative effect [13] on physical exercise in different 
populations. The impact of acculturation on smoking was often modified by gender, with a lower likelihood of smoking in acculturated men and higher likelihood of smoking in acculturated women [14, 15]. Overall, acculturation to unhealthy lifestyles is an important explanation of the elevated risk of many chronic diseases, such as obesity, hypertension, coronary heart disease, diabetes, and cancer, among ethnic minorities in the United States [16].

Researches on the impact of acculturation on systemic health have contributed significantly to our understanding of many health issues, especially the deterioration in immigrants' health after settlement and with each successive generation $[17,18]$. Such a health decline has led to the shift of the "healthy immigrant" phenomenon (i.e. new immigrants are healthier than natives in the host country) to the health disadvantage of immigrants [18]. For maintaining health of the immigrant populations and reducing health disparity, considering the impacts of acculturation is essential, as stressed by numerous professional bodies [16].

In contrast to the long history of acculturation research in the medical arena, the impacts of acculturation on oral health receive attention only in recent years. From 1982 to 1984, the United State conducted the Hispanic Health and Nutrition Examination Survey (HHANES), providing a platform for understanding the relationship between acculturation and various health behaviors and diseases [7, 19, 20]. Utilizing the dental data of this survey, Ismail \& Szpunar analyzed how Mexican Americans with low and high acculturation differed in their use of dental care (dental insurance and dental visit) and oral health (caries and periodontal status) [21]. This became the first study explicitly articulating the term 'acculturation' in the dental context. In the past two decades, although more reports have emerged, the information appeared to be incomplete and fragmented on the relationship between acculturation and oral health. No literature review was published on this issue. As the Surgeon General calls for a better understanding of the cultural factors influencing the oral health of immigrants and ethnic minorities [22], a review on the oral health impact of acculturation would inform future research and policy making. Such information would be useful for effective delivery of interventions and optimal allocation of resources for reducing oral health disparity. In view of the need of synthesizing the research evidence on the oral health impacts of acculturation, we conducted this systematic review, aiming to evaluate the quality of published literatures and summarize the existing findings.

\section{Methods}

This systematic review was performed by both authors who developed the protocol together and conducted the literature search and review following the PRISMA (formerly QUOROM) guideline. When the reviewers disagreed, discussions took place until a consensus was reached.

Acculturation is a multidimensional construct [23]. Traditionally, various proxy measures were used for assessing acculturation [24, 25]. The indicators, used individually, in combination, or integrated as psychometric scales, include language competency or preference, generational status, nativity, age at immigration, length of residence in the host country, ethnic identification, and social affiliation [15, 26].

Publications on the oral health impact of acculturation were searched in January-February 2010 through five electronic databases (PubMed, Medline, Web of Science, Cochrane library, and PsycINFO). Combinations of medical subject headings (MeSH) and key words were used as follows: (acculturation OR transculturation OR cultural adaption/assimilation/acclimation/integration OR ethnic identification OR social affiliation OR nativity OR country of birth OR language preference/use/competency/proficiency OR time/years after/since immigration/immigrating OR time/years/length of residency/residence OR age at immigration OR age of/on arrival) AND (oral health OR oral disease OR dental OR dentistry) AND (immigrant/ immigrants OR ethnic minority/ethnic groups). Papers were selected if the combination of words appeared anywhere in the paper, were published over the period of 1980-2009, and were written in English.

Altogether, 426 papers were retrieved in the primary search of five databases (Fig. 1). These papers were screened by title and abstracts. Three hundred and seventy-seven papers were not related to the impact of acculturation on oral health. Forty-nine reports were identified as potentially relevant to the topic and the full-text papers were obtained. Additional articles were identified from the bibliographies of these 49 papers and reference linked. This further search yielded another 8 more papers. The full articles of these 57 reports were carefully assessed for eligibility. Thirty papers were excluded, while 27 papers were included for this review.

During the screening and selection of papers, the following inclusion criteria were followed: (a) One or more immigrant or ethnic minority group(s) were included in the study; (b) The research analyzed the association between acculturation and at least one oral health behavior or oral disease/condition; (c) Acculturation was measured by at least one clearly defined indicator; (d) Oral health outcome(s) were specified and the method of their measurement was described. A study was excluded if it merely observed oral health of immigrants or ethnic minorities, without analyzing the relationship between their oral health and levels of acculturation. Both cross-sectional and longitudinal studies and both qualitative and quantitative studies were eligible to be included. Commentaries, case reports, and editorials were excluded. 


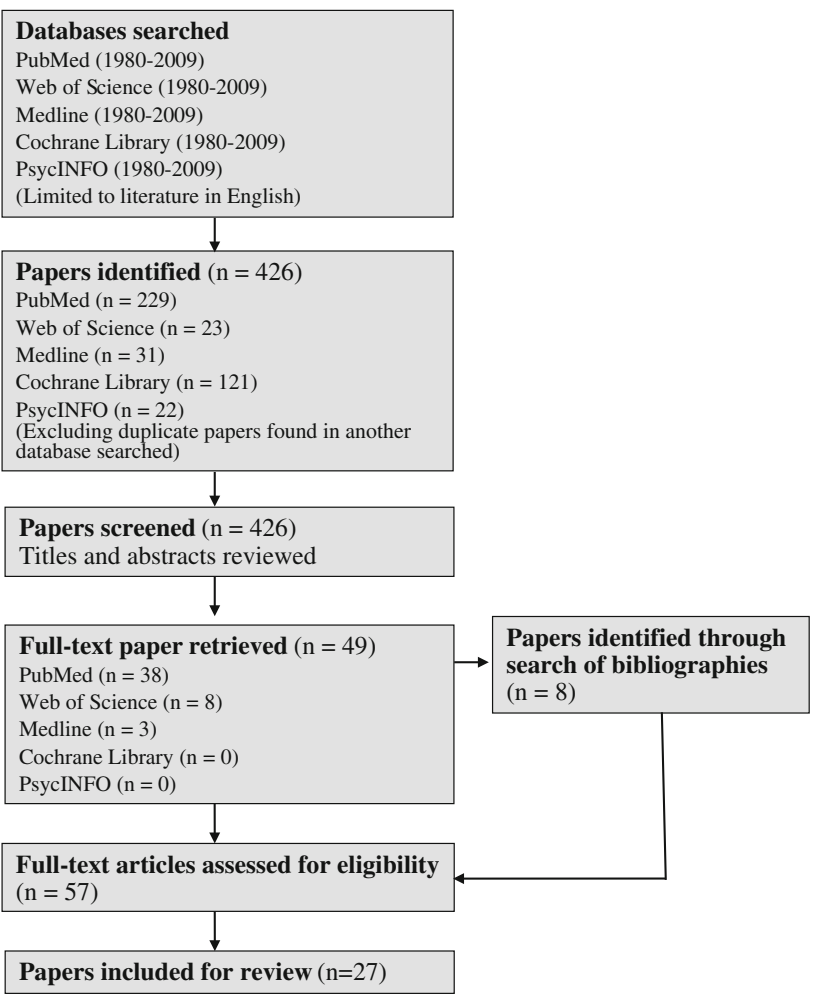

Fig. 1 Flowchart of literature search and selection

The methodological quality of the selected studies was rated according to a scoring tool developed on the basis of a previous work [27]. There are 18 elements in the original scoring tool. Since all studies on acculturation and oral health are observational studies, 5 scoring elements pertaining to interventional studies were excluded. A total of 13 study elements were critically appraised to determine a study quality score (Appendix). Elements reviewed included sample selection, description of the independent variable (acculturation), description of the outcome measure (oral health behavior or disease), reliability and validity of the measurements, blinding, data analyses, and reporting. The possible total scores ranged from 13 to 36 . As recommended, any study with a quality score below $67 \%$ (i.e. 24 ) of the total possible score was to be eliminated from the review [27].

\section{Results}

Quality and Type of Studies

The methodologic quality scores of the 27 selected studies ranged from 26 to 34 , all above $67 \%$ (i.e. 24) of the total possible score (Table 1). Therefore, none of these 27 papers were eliminated from the review.

Ten studies were conducted among Hispanics in the United States (Table 2), with 6 studies in other immigrant or ethnic minority groups in the United States (Table 3). The rest 11 studies were conducted in other countries (Table 4). The age of subjects ranged widely, from $2-5$ to over 70 years. All 27 reports were quantitative cross-sectional studies. Random sampling was adopted in 12 studies, whereas convenience samples were used in other 15 studies.

A variety of acculturation measures used in the medical field were adopted in the dental studies, including single indicators (language, country of birth, age at immigration, and length of residence) used in 14 studies, combination of these indicators in 9 studies and acculturation scales used in 4 studies. The majority (22 out of 27) of studies employed multivariate analysis, in which the impact of acculturation on oral health was evaluated after controlling for demographic and socioeconomic factors. In one study, a data mining tool (KnowledgeSEEKER) was adopted for the analysis.

\section{Acculturation and Utilization of Dental Services}

The impacts of acculturation on utilization of dental services have been investigated in 17 studies. Among them, 16 studies supported a positive association between at least one acculturation indicator and utilization of dental services.

Among Hispanics in the United States (Table 2), data of the HHANES revealed better dental insurance coverage and more dental visits reported by adolescents and adults with higher acculturation, as measured by multidimensional scales [7, 21]. Such a trend was found in all three Hispanic groups (Mexican-American, Cuban-American and Puerto Ricans) [28]. English-speaking Hispanic adults in Florida were more likely to have a dental home, as compared with the non-English-speaking group [29]. In a sample of Hispanic adults who were suffering from orofacial pain, those who were Spanish-speaking or more close to Hispanic culture were less likely to seek treatment and/or have a regular dentist [30]. However, in another study, while the bivariate analysis suggested a link between language preference and dental visit, such association was not significant after controlling for potential confounders in multivariate analysis [31]. In Hispanic farmworker families, dental cares were more received by children born in the United States [32]. However, since this study only adopted bivariate analysis, without controlling for socio-economic factors, the strength of evidence is compromised. As to Hispanic preschoolers, dental visits were more common among those who were local born or English-speaking [33].

Studies among other ethnic minorities in the United States (Table 3) also demonstrated positive impacts of acculturation on utilization of dental care. The use of dental services increased with length of residence in the United States among Chinese elderly immigrants [34] and adults of Hispanic or Asian origins [35], but not among the 


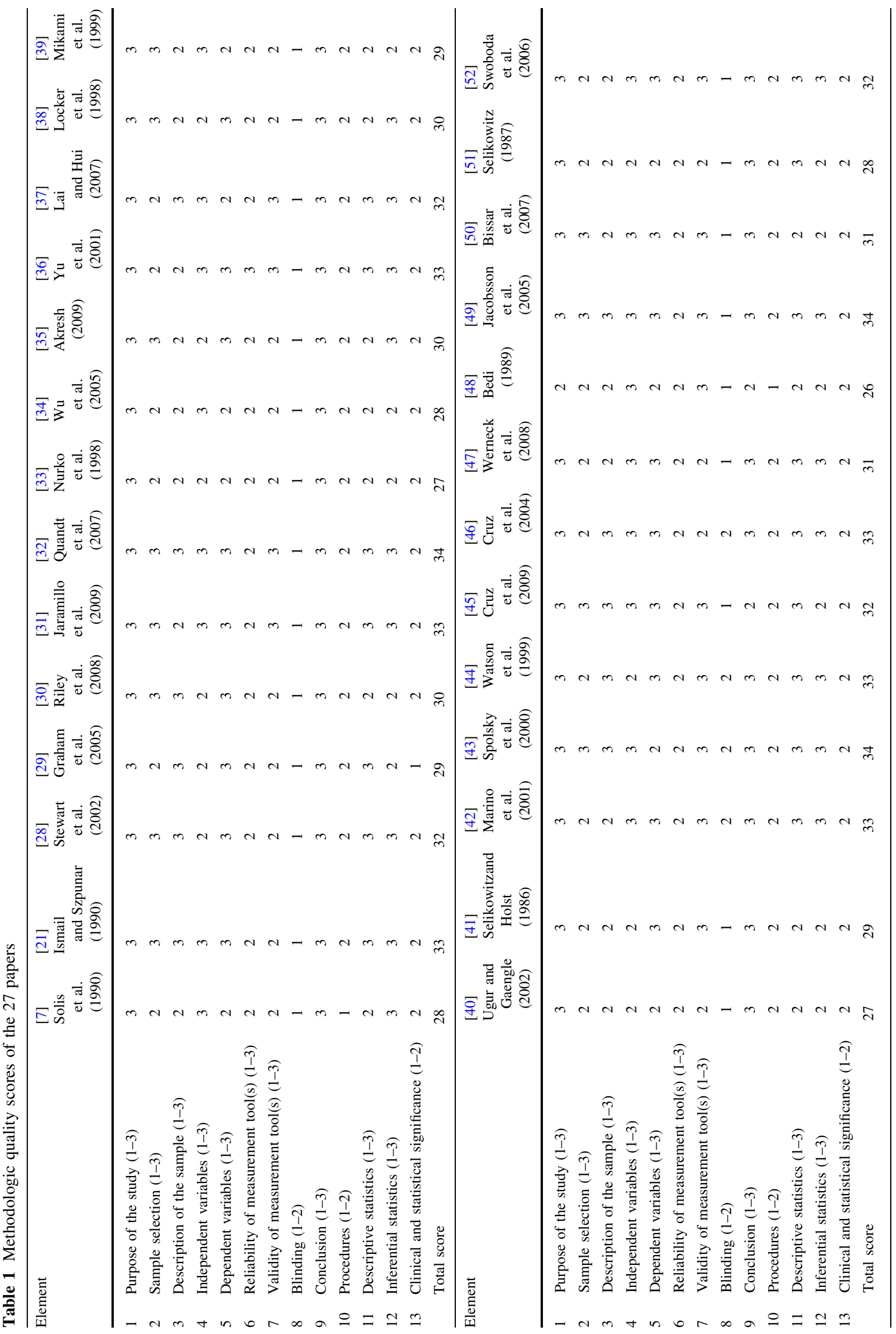


Table 2 Studies among Hispanics in the United States

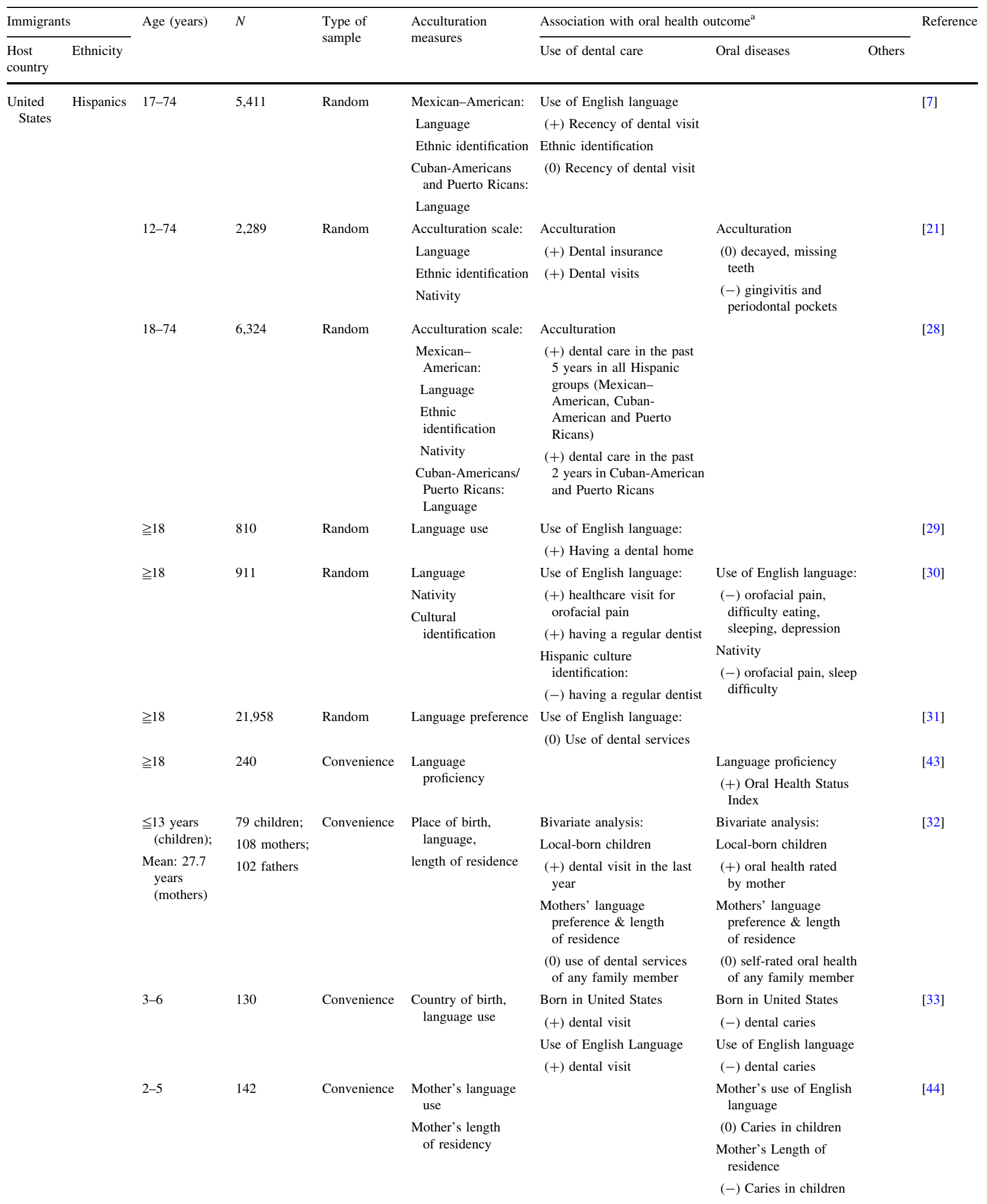

Unless indicated as "bivariate analysis", all results were obtained through multivariate analysis controlling for socioeconomic factors

a $(+)$ positive correlation; $(-)$ negative correlation; $(0)$ no correlation 


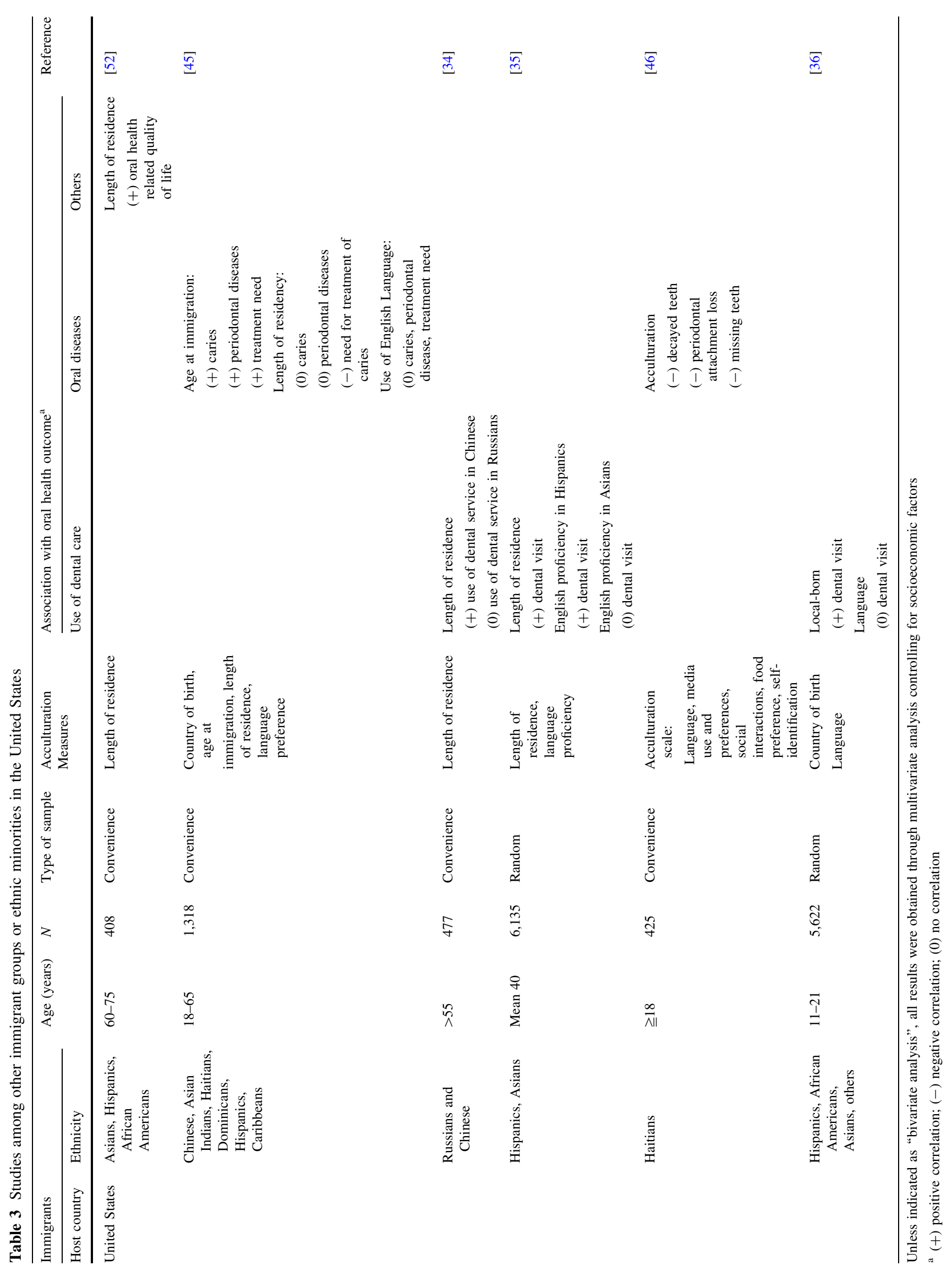


Table 4 Studies in other hosting countries

\begin{tabular}{|c|c|c|c|c|c|c|c|c|c|}
\hline \multicolumn{2}{|l|}{ Immigrants } & \multirow{2}{*}{$\begin{array}{l}\text { Age } \\
\text { (years) }\end{array}$} & \multirow{2}{*}{$N$} & \multirow{2}{*}{$\begin{array}{l}\text { Type of } \\
\text { sample }\end{array}$} & \multirow{2}{*}{$\begin{array}{l}\text { Acculturation } \\
\text { measures }\end{array}$} & \multicolumn{3}{|c|}{ Association with oral health outcome $\mathrm{a}^{\mathrm{a}}$} & \multirow[t]{2}{*}{ Reference } \\
\hline $\begin{array}{l}\text { Host } \\
\text { country }\end{array}$ & Ethnicity & & & & & Use of dental care & Oral diseases & Others & \\
\hline \multirow[t]{3}{*}{ Canada } & Chinese & $\geqq 55 \quad 1$ & 1,537 & Random & $\begin{array}{l}\text { Language } \\
\text { competency } \\
\text { Length of } \\
\text { residency }\end{array}$ & $\begin{array}{l}\text { English Language } \\
\text { competency: } \\
\text { (0) use of dental service } \\
\text { Length of residence } \\
(+) \text { use of dental service }\end{array}$ & & & [37] \\
\hline & $\begin{array}{l}\text { Europeans, } \\
\text { Africans, } \\
\text { Asians, } \\
\text { Central } \\
\text { Americans }\end{array}$ & $13-14$ & & Random & $\begin{array}{l}\text { Length of } \\
\text { residence }\end{array}$ & $\begin{array}{l}\text { Bivariate analysis: } \\
\text { Length of residence } \\
(+) \text { annual dental visit }\end{array}$ & $\begin{array}{l}\text { Bivariate analysis: } \\
\text { Length of residence } \\
\text { (-) calculus } \\
\text { (-) gingivitis } \\
\text { (-) caries } \\
(-) \text { treatment need }\end{array}$ & & {$[38]$} \\
\hline & $\begin{array}{l}\text { Portuguese- } \\
\text { Speaking } \\
\text { Immigrants }\end{array}$ & $\leqq 4$ & 104 & Convenience & $\begin{array}{l}\text { Parents' age at } \\
\text { immigration }\end{array}$ & & $\begin{array}{l}\text { Mother's age at } \\
\text { immigration: } \\
(+) \text { caries in children } \\
\text { Father's age at } \\
\text { immigration: } \\
(+) \text { caries in children }\end{array}$ & & [47] \\
\hline \multirow[t]{2}{*}{$\begin{array}{l}\text { United } \\
\text { Kingdom }\end{array}$} & Japanese & $3-12$ & 161 & Random & $\begin{array}{l}\text { Country of } \\
\text { birth }\end{array}$ & $\begin{array}{l}\text { Bivariate analysis: } \\
\text { Born in United Kingdom } \\
(+) \text { dental visit }\end{array}$ & & $\begin{array}{l}\text { Bivariate analysis: } \\
\text { Born in United } \\
\text { Kingdom } \\
\text { (+) knowledge on } \\
\text { caries }\end{array}$ & [39] \\
\hline & Asians & 5 & 329 & Convenience & $\begin{array}{l}\text { Mother's } \\
\text { language use }\end{array}$ & & $\begin{array}{l}\text { Mother's use of English } \\
\text { language } \\
\text { (-) caries in children }\end{array}$ & $\begin{array}{l}\text { Mother's use of English } \\
(+) \text { oral hygiene of } \\
\text { children }\end{array}$ & [48] \\
\hline Sweden & Not specified & 15 & 131 & Convenience & $\begin{array}{l}\text { Age at } \\
\text { immigration }\end{array}$ & & $\begin{array}{l}\text { Bivariate analysis: } \\
\text { Age at immigration } \\
(+) \text { caries }\end{array}$ & & [49] \\
\hline \multirow[t]{2}{*}{ German } & Turkish & $>12$ & 532 & Convenience & $\begin{array}{l}\text { Language } \\
\text { proficiency }\end{array}$ & $\begin{array}{l}\text { Level of German language } \\
(+) \text { use of dental service }\end{array}$ & & & [40] \\
\hline & $\begin{array}{l}\text { Immigrants } \\
\text { from Turkey, } \\
\text { Poland, } \\
\text { USSR, } \\
\text { Yugosla }\end{array}$ & $12-14$ & 570 & Random & $\begin{array}{l}\text { Country of } \\
\text { birth }\end{array}$ & & $\begin{array}{l}\text { Bivariate analysis: } \\
\text { Born in German } \\
(-) \text { DMFT }\end{array}$ & & {$[50]$} \\
\hline \multirow[t]{2}{*}{ Norway } & Pakistani & $>20$ & 160 & Convenience & $\begin{array}{l}\text { Length of } \\
\text { residence }\end{array}$ & $\begin{array}{l}\text { Length of residence } \\
(+) \text { use of dental care }\end{array}$ & & & [41] \\
\hline & Pakistani & $>20$ & 160 & Convenience & $\begin{array}{l}\text { Length of } \\
\text { residence }\end{array}$ & & $\begin{array}{l}\text { Length of residence } \\
(-) \text { subgingival } \\
\text { calculus } \\
(-) \text { pocket depth }\end{array}$ & & {$[51]$} \\
\hline Australia & Vietnamese & $\geqq 18$ & 147 & Convenience & $\begin{array}{l}\text { Acculturation } \\
\text { scale: } \\
\text { Psychological- } \\
\text { behavioural } \\
\text { acculturation }\end{array}$ & $\begin{array}{l}\text { Psychological acculturation } \\
(+) \text { dental visit (in people } \\
\text { aged } 35 \text { years and above and } \\
\text { had spend } 20 \% \text { of their life } \\
\text { in Australia) }\end{array}$ & $\begin{array}{l}\text { Data mining } \\
\text { (KnowledgeSEEKER) } \\
\text { Medium level of } \\
\text { psychological } \\
\text { acculturation: } \\
\text { High DMFS scores } \\
\text { (among laborers and } \\
\text { students) } \\
\text { Behavioral acculturation } \\
\text { (-) DMFS (for young } \\
\text { adult aged } \\
\text { 18-35 years and not } \\
\text { working outside } \\
\text { home) }\end{array}$ & $\begin{array}{l}\text { Data mining } \\
\text { (KnowledgeSEEKER) } \\
\text { Medium level of } \\
\text { psychological } \\
\text { acculturation: } \\
\text { Poor oral health } \\
\text { knowledge }\end{array}$ & [42] \\
\hline
\end{tabular}

Unless indicated as "bivariate analysis", all results were obtained through multivariate analysis controlling for socioeconomic factors

${ }^{\text {a }}(+)$ positive correlation; $(-)$ negative correlation; $(0)$ no correlation 
Russian elderly [34]. English proficiency was associated with dental visit in Hispanic adults but not in Asians [35]. Among adolescents of various origins, those born in other countries were less likely to visit dentists [36].

Similar findings exist in other host countries (Table 4). In Canada, use of dental services increased with length of residence among the elderly of Chinese origin [37] and among adolescents of various origins (bivariate analysis) [38]. In the United Kingdom, local-born children of Japanese origin tended to visit dentists more often, compared with those born in Japan (bivariate analysis) [39]. Among Turkish immigrants in Germany, proficiency in German language indicated a tendency of using dental services [40]. Among Pakistani immigrants in Norway, use of dental care increased with their residence in the host country [41]. Using a psychometric scale, authors reported that psychological acculturation facilitated dental visit of Vietnamese immigrants who were 35 years and above and who had spend $20 \%$ of their life in Australia [42].

\section{Acculturation and Oral Diseases}

The association of acculturation and oral diseases has been evaluated in 15 studies. Caries and/or periodontal diseases were the main diseases outcomes in all studies, except for a study concerning orofacial pain and its complications. All 15 studies supported positive impacts of acculturation on oral health.

Among Hispanics in the United States (Table 2), the HHANES survey, using a multidimensional acculturation scale, showed a reduced prevalence of gingivitis and periodontal pockets in highly acculturated adolescents and adults [21]. In Hispanic adults with orofacial pain, those who were English-speaking or with high nativity suffered less from the pain and its complications [30]. In another group of Hispanic adults, acculturation measured by English language proficiency indicated higher Oral Health Status Index, a score integrating the tooth and periodontium status [43]. In Latino farmworker families, compared with foreign-born children, those local-born had a better oral health, as rated by mothers (bivariate analysis) [32]. Among Hispanic preschool children, being born in the United States, speaking English [33], and mother's longer residence in the United States [44] implied lower rate of early childhood caries.

Observations in other ethnic minority groups (Table 3) showed that adults who immigrated to the United States at an older age had higher prevalence of caries and periodontal diseases and higher treatment needs [45]. In a sample of adult Haitian immigrants living in New York City, higher acculturation defined by a multidimensional scale was linked to lower rates of caries, periodontal attachment loss, and missing teeth [46].
In other countries (Table 4), a Canadian report showed that, the presence of calculus, gingivitis, caries and treatment needs among adolescent immigrants decreased with their length of residence (results from bivariate analysis) [38]; among Portuguese-speaking immigrants, parents who had immigrated in their 20 s or at an older age were 2-4 times more likely to have a child with early childhood caries than those who immigrated at a younger age [47]. In the United Kingdom, Asian women who spoke English were less likely to have a child with caries [48]. In Sweden, adolescents who were second generation immigrants or who had arrived before 1 year of age had a caries prevalence similar to those of native adolescents, whereas those who arrived after 7 years of age had a caries prevalence that was 2-3 times higher (bivariate analysis) [49]. In German, a lower DMFT was found among local-born adolescent immigrants, as compared with their foreignborn counterpart (bivariate analysis) [50]. Compared with new arrivals, Pakistani immigrants who had lived in Norway for a longer period of time had better periodontal condition, indicated by the subgingival calculus and pocket depth [51]. Using a data mining tool KnowledgeSEEKER, a study among Vietnamese in Australia showed that, while behavioral acculturation reduced the caries rate in young adults not working outside home, the relationship between psychological acculturation and caries was non-linear, as laborers and students with a medium level of psychological acculturation had significantly higher DMFS scores than those with low or high acculturation [42].

\section{Acculturation and Other Oral Health Outcomes}

A report among the elderly of multiple ethnic groups has demonstrated improvement in oral health-related quality of life with the length of residence in the United States (Table 3) [52]. In the United Kingdom (Table 4), favorable oral health knowledge of Japanese children was associated with being local-born (bivariate analysis) [39]; satisfactory oral hygiene of Asian immigrant children was linked to mother's use of English language [48]. In Australia, Vietnamese immigrants with medium level of acculturation had significantly lower oral health knowledge scores than those in the low and high acculturation categories (Table 4) [42].

\section{Discussion}

Oral Health Impacts of Acculturation

While 3 reports published in 1980s has probed the impact of acculturation on oral health, 6 more papers emerged in $1990 \mathrm{~s}$ and 18 articles were published in the last 10 years (2000-2009). This shows an increasing attention paid to this 
public health issue. In some of the early works, acculturation was not explicitly conceptualized as the phenomenon under investigation [38, 41, 44, 48, 51]. However, as these early studies have associated some acculturation variables (e.g. language use, length of residence) with oral health, such findings have laid a foundation for further scrutinizing the oral health implications of acculturation.

Considering the diverse populations investigated, in this review we have summarized results from different populations (Tables 2, 3, 4) separately. It is however interesting to find similar trends existing in different counties. Since immigration is normally from less developed world to developed countries, acculturation is often a cultural transition to modern lifestyles. Despite the differences in dental care system across nations, dental treatments are often not extensively subsidized, leading to similar impacts of acculturation on utilization of dental care in different host countries.

In aggregation, the existing reports have provided substantial evidence on a positive effect of acculturation on immigrants' utilization of dental services. This is in line with the findings of medical studies, which repetitively demonstrated that acculturated immigrants are more likely to use medical services $[7,8]$. Such impact of acculturation has its theoretical plausibility as people's utilization of health care might be largely shaped by the culture of a community, such as the cultural norms and beliefs (e.g. fatalism), faith on other cures [53], and ethnic beliefs on disease causation and prevention [54, 55]. Most of the studies adopted multivariate analysis, in which socioeconomic factors were controlled for. Therefore, the impact of acculturation on improving use of dental care revealed in these studies is not attributable to improved socio-economic circumstances after settlement. However, comprehensively adjustment for other confounders or risk factors is not seen in the existing report and may be considered in future research.

It should be borne in mind that increased utilization of dental services along acculturation may not necessarily lead to improved oral health. Our review identified only 6 studies which simultaneously observed utilization of dental care and oral health. Moreover, all 15 studies observing oral diseases/conditions focused on dental caries and periodontal diseases, with only one exception involving orofacial pain. Future studies on other oral conditions are warranted for a more complete understanding on the dental impact of acculturation. For example, the use of indigenous tobacco and areca products, which are proven carcinogenic, is common in some South Asian countries such as India and Bangladesh [56]. This has led to a high oral cancer rate in these ethnic groups [56]. Observations on the immigrants' use of these carcinogic products and their oral cancer prevalence along the acculturation process will provide important reference for formulating timely and effective interventions.

Social science studies have uncovered a complex pattern of acquisition and loss along acculturation [57, 58]. It has been postulated that partial acculturation may put immigrants at a greater risk for adverse health outcomes [59]. Utilizing an advanced data mining method, a dental study has revealed a high caries rate and poor oral health knowledge in immigrants with medium level of psychological acculturation [42]. This finding, revealing the non linear effect of acculturation on dental status, lends support to the 'cultural marginality model', which proposes that the partially acculturated individual, who is alienated from their traditional culture, but not yet integrated into the dominant culture, will be most susceptible to diseases [60]. While most public health programs target new arrivals, this research have underpinned the importance of tailored interventions for the partially acculturated immigrants.

Since acculturation embraces changes in belief, behaviors, and lifestyles after one's contact with a new culture, it is intuitively and theoretically attractive to assume that the impacts of acculturation on health are mediated by the changes of health behaviors $[9,11,16]$. Numerous medical studies investigating how acculturation shapes health behaviors have yielded enlightening findings [10, 12, 15]. Nevertheless, there is a dearth of dental research addressing the impacts of acculturation on oral health self-care behaviors (diet, oral hygiene etc). This hampers the delivery of effective oral health interventions. The negative impact of acculturation on health behaviours found in some medical studies [9-12] has not been reported in dental research. However, concrete conclusions may only be drawn after more oral health behaviours are investigated in the context of acculturation.

\section{Limitations of Current Evidence}

Measuring acculturation is a complex undertaking. In medical literatures, various psychometric acculturation scales and common proxy measures (e.g. language preference) have been used [5]. It was advocated that the selection of acculturation measure should be based on the cultural context of a particular population [5]. Multidimensional scales developed for various immigrant groups may profile acculturation comprehensively [24, 25]; nevertheless, it has rarely been used in dental studies. Meanwhile, studies are lacking on the impacts of acculturation on oral health self-care behaviours and a variety of oral diseases and conditions. Also worth noting are the methodological flaws (e.g. inadequate control for confounders) of some studies. These limitations should be taken into consideration in interpreting and appraising the evidence from individual studies. 


\section{Future Direction}

Greater clarity on the oral health impacts of acculturation would come from future research involving a constellation of oral health behaviors and diseases, incorporating multidimensional acculturation scales, and employing multivariate analytical approaches. Equally importantly, as acculturation should be measured as a process rather than a state, prospective studies may further our understanding on the trajectory of immigrants' oral health along the acculturation continuum. In addition, acculturation is bidirectional and reciprocal [2], rather than being limited to the minority groups. It is therefore relevant to profile the acculturation occurring in the mainstream (local) population of an ethnically diversified society and understand how such accuturation affects oral health. Qualitative researches may play an important role in understanding the acculturation phenomenon and its multifaceted implications on oral health.

Open Access This article is distributed under the terms of the Creative Commons Attribution Noncommercial License which permits any noncommercial use, distribution, and reproduction in any medium, provided the original author(s) and source are credited.

\section{Appendix}

See Table 5 .

Table 5 Methodologic quality assessment criteria

\begin{tabular}{|c|c|c|}
\hline & Element & Criteria \\
\hline 1 & Purpose of the study & $\begin{array}{l}\text { 3-Clearly defined } \\
\text { 2-Unclearly defined } \\
\text { 1-No definition provided }\end{array}$ \\
\hline 2 & Sample selection & $\begin{array}{l}\text { 3-Random sampling } \\
\text { 2-Non-random sampling } \\
\text { 1-Not described }\end{array}$ \\
\hline 3 & Description of the sample & $\begin{array}{l}\text { 3-Complete and comprehensive } \\
\text { 2-Incomplete } \\
\text { 1-Not described }\end{array}$ \\
\hline 4 & Independent variables & $\begin{array}{l}\text { 3-Clearly defined } \\
\text { 2-Unclearly defined } \\
\text { 1-Not defined }\end{array}$ \\
\hline 5 & Dependent variables & $\begin{array}{l}\text { 3-Clearly defined } \\
\text { 2-Unclearly defined } \\
\text { 1-Not defined }\end{array}$ \\
\hline 6 & Reliability of measurement tool(s) & $\begin{array}{l}\text { 3-Reliable } \\
\text { 2-Tool is reliable but data on reliability are not reported } \\
\text { 1-Not reliable/no information provided }\end{array}$ \\
\hline 7 & Validity of measurement tool(s) & $\begin{array}{l}\text { 3-Valid and used with the population and in the setting for } \\
\text { which it is intended } \\
\text { 2-Tool is known to be valid but the authors did not use it with } \\
\text { the population or in the setting for which it is intended } \\
\text { 1-Not valid/no information provided }\end{array}$ \\
\hline 8 & Blinding & $\begin{array}{l}\text { 2-Is present } \\
1 \text {-Is not present }\end{array}$ \\
\hline 9 & Conclusion & $\begin{array}{l}\text { 3-All subjects are accounted for } \\
\text { 2-Only some subjects are accounted for } \\
\text { 1-No such information provided }\end{array}$ \\
\hline 10 & Procedures & $\begin{array}{l}\text { 2-Described in sufficient detail to permit replication } \\
\text { 1-Unclearly described and do not permit replication }\end{array}$ \\
\hline 11 & Descriptive statistics & $\begin{array}{l}\text { 3-Provided and appropriate } \\
\text { 2-Provided but inappropriate } \\
\text { 1-Not provided at all }\end{array}$ \\
\hline
\end{tabular}


Table 5 continued

\begin{tabular}{lll}
\hline & Element & Criteria \\
\hline 12 & Inferential statistics & 3-Provided and appropriate \\
& 2-Provided but inappropriate \\
& 1-Not provided at all \\
& Clinical and statistical significance & 2-Statistically and clinically significant or statistically insignificant \\
& with sufficient power \\
& 1-Statistically significant/not clinically significant or statistically \\
& insignificant with insufficient power or not discussed \\
& Total score & \\
\hline
\end{tabular}

Adapted from the scoring system developed by Chan and Bartlett [27]

\section{References}

1. Martin P, Midgley E: Immigration: shaping and reshaping America. Popul Bull. 2006;61.

2. Redfield R, Linton R, Herskovits MJ. Memorandum for the study of acculturation. Am Anthropol. 1936;38:149-52.

3. Berry JW. Conceptual approaches to acculturation. In: Chun KM, Organista PB, Marín G, editors. Acculturation: advances in theory, measurement and applied research. Washington, D.C.: American Psychological Assoc.; 2003. pp. 17-37.

4. Henry JP, Cassel JC. Psychosocial factors in essential hypertension. Recent epidemiologic and animalexperimental evidence. Am J Epidemiol. 1969;90(3):171-200.

5. Hunt LM, Schneider S, Comer B. Should 'acculturation' be a variable in health research? A critical review of research on US Hispanics. Social Sci Med. 2004;59:973-86.

6. Franzini L, Ribble JC, Keddie AM. Understanding the Hispanic paradox. Ethn Dis. 2001;11:496-518.

7. Solis JM, Marks G, Garcia M, Shelton D. Acculturation, access to care, and use of preventive services by Hispanics: findings from HHANES 1982-1984. Am J Public Health. 1990;80:11-9.

8. Lara M, Gamboa C, Kahramanian MI, Morales LS, Bautista DEH. Acculturation and Latino health in the United States: A review of the literature and the sociopolitical context. Ann Rev Public Health. 2005;26:367-97.

9. Caetano R. Acculturation and drinking patterns among U.S. Hispanics. Br J Addict. 1987;82:789.

10. Otero-Sabogal R, Sabogal F, Perez-Stable EJ, Hiatt RA. Dietary practices, alcohol consumption, and smoking behavior: ethnic, sex, and acculturation differences. J Natl Cancer Inst Monogr. 1995; 18:73-82.

11. Lee S, Sobal J, Frongillo EA. Acculturation and health in Korean Americans. Soc Sci Med. 2000;51:159-73.

12. Ayala GX, Baquero B, Klinger S. A systematic review of the relationship between acculturation and diet among Latinos in the United States: implications for future research. J Am Diet Assoc. 2008;108(8):1330-44.

13. Huang B, Rodriguez B, Burchfiel CM, Chyou P, Curb DJ. Acculturation and prevalence of diabetes among JapaneseAmerican men in Hawaii. Am J Epidemiol. 1996;144:674-81.

14. Bethel JW, Schenker MB. Acculturation and smoking patterns among Hispanics: a review. Am J Prev Med. 2005;29(2):143-8.

15. Choi S, Rankin S, Stewart A, Oka R. Effects of Acculturation on Smoking Behavior in Asian Americans: A Meta-Analysis. J Cardiovasc Nurs. 2008;23(1):67-73.

16. Ver Ploeg M, Perrin E. Eliminating health disparities. Measurement and Data Needs. National Research Council, Washington, DC: National Academies Press; 2004.
17. Harris KM. The health status and risk behaviors of adolescents in immigrant families. In: Hernandez DJ, editor. Children of immigrants. Washington, DC: National Academy Press; 1999; 286-315.

18. LaVeist T. Race, ethnicity, and health: a public health Reader. New York: Jossey-Bass; 2002.

19. Espino DV, Maldonado D. Hypertension and acculturation in elderly Mexican Americans: results from 1982-84 Hispanic HANES. J Gerontol. 1990;45(6):M209-13.

20. Haynes SG, Harvey C, Montes H, Nickens H, Cohen BH. Patterns of cigarette smoking among Hispanics in the United States: Results from HHANES 1982-1984. Am J Public Health. 1990; 80(Suppl):47-53.

21. Ismail AI, Szpunar SM. Oral health status of Mexican-Americans with low and high acculturation status: Findings from southwest HHANES, 1982-84. J Public Health Dent. 1990;50:24-31.

22. U.S. Department of Health and Human Services (US/DHHS): Oral health in America: A report of the surgeon general. Rockville, MD: US Department of Health and Human Services, National Institutes of Health, National Institute of Dental and Craniofacial Research, NIH publication 00-4713;2000.

23. Berry JW. Immigration acculturation and adaptation. Applied Psychology. 1997;46:5-68.

24. Flannery DJ, Reise SP, Yu J. An empirical comparison of acculturation models. Pers Soc Psychol Bull. 2001;27:1035-45.

25. Phinney JS, Flores J. "Unpackaging" acculturation: aspects of acculturation as predictors of traditional sex role attitudes. J Cross Cult Psychol. 2002;33:320-31.

26. Beck C. Acculturation: implications for perinatal research. MCN Am J Matern Child Nurs 2006;31(2):114-20.

27. Chan WW, Bartlett DJ. Effectiveness of Tai Chi as a therapeutic exercise in improving balance and postural control. Phys Occup Therapy Geriatr. 2000;17(3):1-22.

28. Stewart DC, Ortega AN, Dausey D, Rosenheck R. Oral health and use of dental services among Hispanics. J Public Health Dent. 2000;62(2):84-91.

29. Graham MA, Tomar SL, Logan HL. Perceived social status, language and identified dental home among Hispanics in Florida. J Am Dent Assoc. 2005;136(11):1572-82.

30. Riley JL 3rd, Gibson E, Zsembik BA, Duncan RP, Gilbert GH, Heft MW. Acculturation and orofacial pain among Hispanic adults. J Pain. 2008;9(8):750-8.

31. Jaramillo F, Eke PI, Thornton-Evans GO, Griffin SO. Acculturation and dental visits among Hispanic adults. Prev Chronic Dis. 2009;6(2):A50.

32. Quandt SA, Clark HM, Rao P, Arcury TA. Oral health of children and adults in Latino migrant and seasonal farmworker families. J Immigr Minor Health. 2007;9(3):229-35. 
33. Nurko CL, Aponte-Merced L, Bradley EL, Fox L. Dental caries prevalence and dental health care of Mexican-American workers' children. ASDC J Dent Child. 1998;65(1):65-72.

34. Wu BT, Tran V, Khatutsky G. Comparison of utilization of dental care services among Chinese- and Russian-speaking immigrant elders. J Public Health Dent. 2005;65(2):97-103.

35. Akresh IR: Health service utilization among immigrants to the United States. Popul Res Policy Rev. 2009;28(6):795-815.

36. Yu SM, Bellamy HA, Schwalberg RH, Drum MA. Factors associated with use of preventive dental and health services among U.S. adolescents. J Adolesc Health. 2001;29(6):395-405.

37. Lai DW, Hui NT. Use of dental care by elderly Chinese immigrants in Canada. J Public Health Dent. 2007;67(1):55-9.

38. Locker D, Clarke M, Murray H. Oral health status of Canadianborn and immigrant adolescents in North York, Ontario. Community Dent Oral Epidemiol. 1998;26(3):177-81.

39. Mikami YR, Croucher R, Hector M. Knowledge and reported behaviour concerning the prevention of caries in children: a questionnaire survey of Japanese parents resident in London, UK. Int Dent J. 1999;49(2):115-21.

40. Ugur ZA, Gaengler P. Utilisation of dental services among a Turkish population in Witten, Germany. Int Dent J. 2002;52(3): 144-50.

41. Selikowitz HS, Holst D. Dental health behavior in a migrant perspective: use of dental services of Pakistani immigrants in Norway. Commun Dent Oral Epidemiol. 1986;14(6):297-301.

42. Marino R, Stuart GW, Wright FA, Minas IH, Klimidis S. Acculturation and dental health among Vietnamese living in Melbourne, Australia. Commun Dent Oral Epidemiol. 2001;29: 107-19.

43. Spolsky VW, Marcus M, Coulter ID, Der-Martirosian C, Atchison KA. An empirical test of the validity of the Oral Health Status Index (OHSI) on a minority population. J Dent Res. 2000;79:1983-8.

44. Watson MR, Horowitz AM, Garcia I, Canto MT. Caries conditions among 2-5-year-old immigrant Latino children related to parents' oral health knowledge, opinions and practices. Community Dent Oral Epidemiol. 1999;27(1):8-15.

45. Cruz GD, Chen Y, Salazar CR, Le Geros RZ. The association of immigration and acculturation attributes with oral health among immigrants in New York City. Am J Public Health. 2009; 99(Suppl 2):S474-80.

46. Cruz GD, Shore R, Le Geros RZ, Tavares M. Effect of acculturation on objective measures of oral health in Haitian immigrants in New York City. J Dent Res. 2004;83(2):180-4.
47. Werneck RI, Lawrence HP, Kulkarni GV, Locker D. Early childhood caries and access to dental care among children of Portuguese-speaking immigrants in the city of Toronto. J Can Dent Assoc. 2008;74(9):805.

48. Bedi R. Ethnic indicators of dental health for young Asian schoolchildren resident in areas of multiple deprivation. Br Dent $\mathrm{J}$ 1989;166(9):331-334.

49. Jacobsson B, Wendt LK, Johansson I. Dental caries and caries associated factors in Swedish 15-year-olds in relation to immigrant background. Swed Dent J. 2005;29(2):71-9.

50. Bissar AR, Schulte AG, Muhjazi G, Koch MJ, Schulte AG. Caries prevalence in 11- to 14-year old migrant children in Germany. Int J Public Health. 2007;52(2):103-8.

51. Selikowitz HS. The relationship between periodontal conditions and perceptions of periodontal health among Pakistani immigrants in Norway. J Clin Periodontol 1987;14(6):340-344.

52. Swoboda J, Kiyak HA, Persson RE, Persson GR, Yamaguchi DK, MacEntee MI, Wyatt CC. Predictors of oral health quality of life in older adults. Spec Care Dentist. 2006;26(4):137-44.

53. Lee KL, Schwarz E, Mak KYK. Improving oral health through understanding the meaning of health and culture in a Chinese culture. Int Dent J. 1993;43:2-8.

54. Hilton IV, Stephen S, Barker JC, Weintraub JA. Cultural factors and children's oral health care: a qualitative study of carers of young children. Community Dent Oral Epidemiol. 2007;35: 429-38.

55. Zhang W. Chinese culture and dental behaviour: some observations from Wellington. N Z Dent J. 2009;105(1):22-27.

56. Changrani J, Gany F. Paan and Gutka in the United States: an emerging threat. J Immigr Health. 2005;7(2):103-8.

57. Meston CM, Trapnell PD, Gorzalka BB. Ethnic and gender differences in sexuality: variations in sexual behavior between Asian and non-Asian university students. Arch Sex Behav. 1996;25(1): $33-72$.

58. Yi JK. Vietnamese American college students' knowledge and attitudes toward HIV/AIDS. J Am Coll Health 1998;47(1):37-42.

59. Choi H. Cultural marginality: a concept analysis with implications for immigrant adolescents. Issues Compr Pediatr Nurs. 2001;24(3):193-206.

60. Neff JA, Hoppe SK. Race/ethnicity, acculturation and psychological distress: fatalism and religiosity as cultural resource. J Comm Psychol. 1993;21:3-20. 